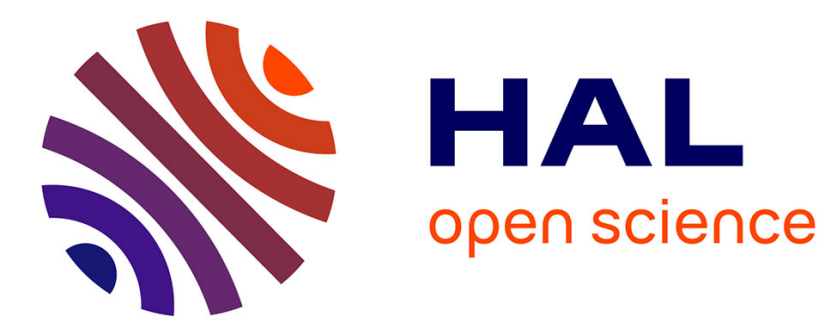

\title{
Active and passive earth pressure coefficients by a kinematical approach
}

\author{
Abdul-Hamid Soubra, B. Macuh
}

\section{To cite this version:}

Abdul-Hamid Soubra, B. Macuh. Active and passive earth pressure coefficients by a kinematical approach. Proceedings of the ICE - Geotechnical Engineering, 2002, 155 (2), pp.119-131. 10.1680/geng.2002.155.2.119 . hal-01004976

\section{HAL Id: hal-01004976 https://hal.science/hal-01004976}

Submitted on 21 Feb 2017

HAL is a multi-disciplinary open access archive for the deposit and dissemination of scientific research documents, whether they are published or not. The documents may come from teaching and research institutions in France or abroad, or from public or private research centers.
L'archive ouverte pluridisciplinaire HAL, est destinée au dépôt et à la diffusion de documents scientifiques de niveau recherche, publiés ou non, émanant des établissements d'enseignement et de recherche français ou étrangers, des laboratoires publics ou privés. 


\title{
Active and passive earth pressure coefficients by a kinematical approach
}

\author{
A.-H. Soubra and B. Macuh
}

\begin{abstract}
A simple method is proposed for calculating the active and passive earth pressure coefficients in the general case of an inclined wall and a sloping backfill. The approach used is based on rotational log-spiral failure mechanisms in the framework of the upper-bound theorem of limit analysis. It is shown that the energy balance equation of a rotational log-spiral mechanism is equivalent to the moment equilibrium equation about the centre of the log-spiral. Numerical optimisation of the active and passive earth pressure coefficients is performed automatically by a spreadsheet optimisation tool. The implementation of the proposed method is illustrated using an example. The predictions by the present method are compared with those given by other authors.
\end{abstract}

\section{NOTATION \\ c \\ $\mathrm{d} l$ \\ $\dot{D}$ \\ $f_{1}, f_{2}, \ldots, f_{8}$ \\ $K_{\gamma}, K_{\mathrm{q}}, K_{\mathrm{c}}$ \\ $K_{\mathrm{a} \gamma}, K_{\mathrm{aq}}, K_{\mathrm{ac}}$ \\ $K_{\mathrm{p} \gamma}, K_{\mathrm{pq}}, K_{\mathrm{pc}}$ \\ $K_{\text {aq0 }}, K_{\text {pq0 }}$}

$l / r_{0}$ and $L / r_{0}$

$l$

$L$

$P_{\mathrm{a}}, P_{\mathrm{p}}$

$P_{\text {ad }}$

$q$

$q_{0}$

$r_{0}, r_{1}$

V

W

$\dot{W}$

$\alpha$

$\beta$

$\gamma$ cohesion

elementary length along the slip surface BC

rate of energy dissipation

intermediate non-dimensional functions

earth pressure coefficients due to soil weight, vertical surcharge loading and cohesion active earth pressure coefficients passive earth pressure coefficients active and passive earth pressure coefficients due to a surcharge loading normal to the

intermediate non-dimensional functions

wall length

length of $A B$

adhesive force

vertical surcharge loading

surcharge loading normal to the ground

surface

initial and final radius of the log-spiral slip

surface

velocity at the velocity discontinuity

weight of the soil mass $A B C$

rate of work of an external force

inclination of the Rankine earth pressure

slope of the backfill

unit weight of the soil ground surface

active and passive forces respectively $\delta$

$\theta_{0}, \theta_{1}$

$\lambda$

$\xi$

$\sigma$

$\tau$

$\phi$

$\Omega$

\author{
friction angle at the soil-structure interface \\ angles defining the log-spiral slip surface \\ angle between the soil-wall interface and the \\ vertical direction \\ inclination of the Rankine slip surface with \\ the horizontal direction \\ normal stress acting on the slip surface \\ tangential stress acting on the slip surface \\ angle of internal friction of the soil \\ angular velocity of failure mechanism
}

\section{INTRODUCTION}

The problem of active and passive earth pressures acting against rigid retaining structures has been extensively studied in the literature since Coulomb. ${ }^{1}$ Most of the existing methods are based on either the limit equilibrium method, the slip line method or the limit analysis method.

Recently, a variational analysis has been applied to the passive earth pressure problem by Soubra et al. ${ }^{2}$ Their approach is based on a limit equilibrium method, and the solution provides a log-spiral failure surface. For their failure wedge, the moment equilibrium equation can be used for the calculation of the passive earth pressures without specifying the normal stress distribution along the log-spiral slip surface. It should be emphasised that their method, employed in this paper, can be categorised also as an upper-bound in the framework of limit analysis where a rotational rigid body movement is considered. This variational limit equilibrium method may be easily extended to the active earth pressure problem, and the same conclusions remain valid in this case:

(a) A log-spiral failure surface may be obtained from a variational maximisation procedure.

(b) The moment equilibrium equation, which is equivalent to the energy balance equation in the framework of the upper-bound method of limit analysis, may be used for computation of the active earth pressures.

The aim of this paper is to show that the upper-bound method in limit analysis for a rotational log-spiral failure mechanism gives rapid and good predictions for both active and passive earth pressures. It is also demonstrated that the present method can be easily implemented on a PC by defining spreadsheet 
functions and by using a powerful spreadsheet optimisation tool. The analysis is made in the general case of an inclined wall and a sloping backfill, and considers a frictional and cohesive $(c, \phi)$ soil. A uniform surcharge is assumed to act on the ground surface. Active and passive earth pressure coefficients due to soil weight, cohesion and surcharge loading are presented for various governing parameters and compared with those given by other authors.

\section{FAILURE MECHANISMS AND GOVERNING EQUATIONS}

The variational analysis details and the equivalence between the variational limit equilibrium method and the upper-bound method in limit analysis for a rotational log-spiral failure mechanism are given elsewhere. ${ }^{2}$ However, for clarity, only the upper-bound technique (that is, the kinematical approach) of limit analysis is briefly described here.

Two rotational log-spiral failure mechanisms are considered in the present analysis, one for the active state M1 (Fig. 1(a)) and the other for the passive state M2 (Fig. 1(b)). For both M1 and $\mathrm{M} 2$ mechanisms, the region $\mathrm{ABC}$ rotates as a rigid body about the as yet undefined centre of rotation 0 relative to the material below the logarithmic failure surface BC. Thus the surface BC is a surface of velocity discontinuity. These failure mechanisms can be specified completely by two variables $\theta_{0}$ and $\theta_{1}$. It should be emphasised that the earth pressure coefficient due to soil weight, $K_{\gamma}$, is calculated with the assumption of a cohesionless soil with no surcharge loading. The computation of the coefficients $K_{\mathrm{q}}$ and $K_{\mathrm{c}}$ due to surcharge loading and cohesion is based on the assumption of a weightless soil with $\mathrm{c}=0$ for $K_{\mathrm{q}}$ and $q=0$ for $K_{\mathrm{c}}$. The formulation for the coefficients of earth pressure due to soil weight, surcharge and cohesion follows.

\section{I. Rate of work of external forces}

As shown in Fig. 1, the external forces acting on the soil mass in motion consist of the self-weight of the soil, $W$, the active or passive earth force $\left(P_{\mathrm{a}}\right.$ or $\left.P_{\mathrm{p}}\right)$, the adhesive force, $P_{\text {ad }}(=c l \tan \delta / \tan \phi)$, and the surcharge, $q L$, acting on the ground surface. The rate of work for the different external forces can be calculated as follows.

\subsubsection{Rate of work of the soil weight. A direct integration of} the rate of work of the soil weight in the region $A B C$ is very complicated. An easier alternative is first to find the rate of work $\dot{W}_{\mathrm{OBC}}, \dot{W}_{\mathrm{OAB}}$ and $\dot{W}_{\mathrm{OAC}}$ due to soil weight in the regions $\mathrm{OBC}, \mathrm{OAB}$ and $\mathrm{OAC}$ respectively. The rate of work for the

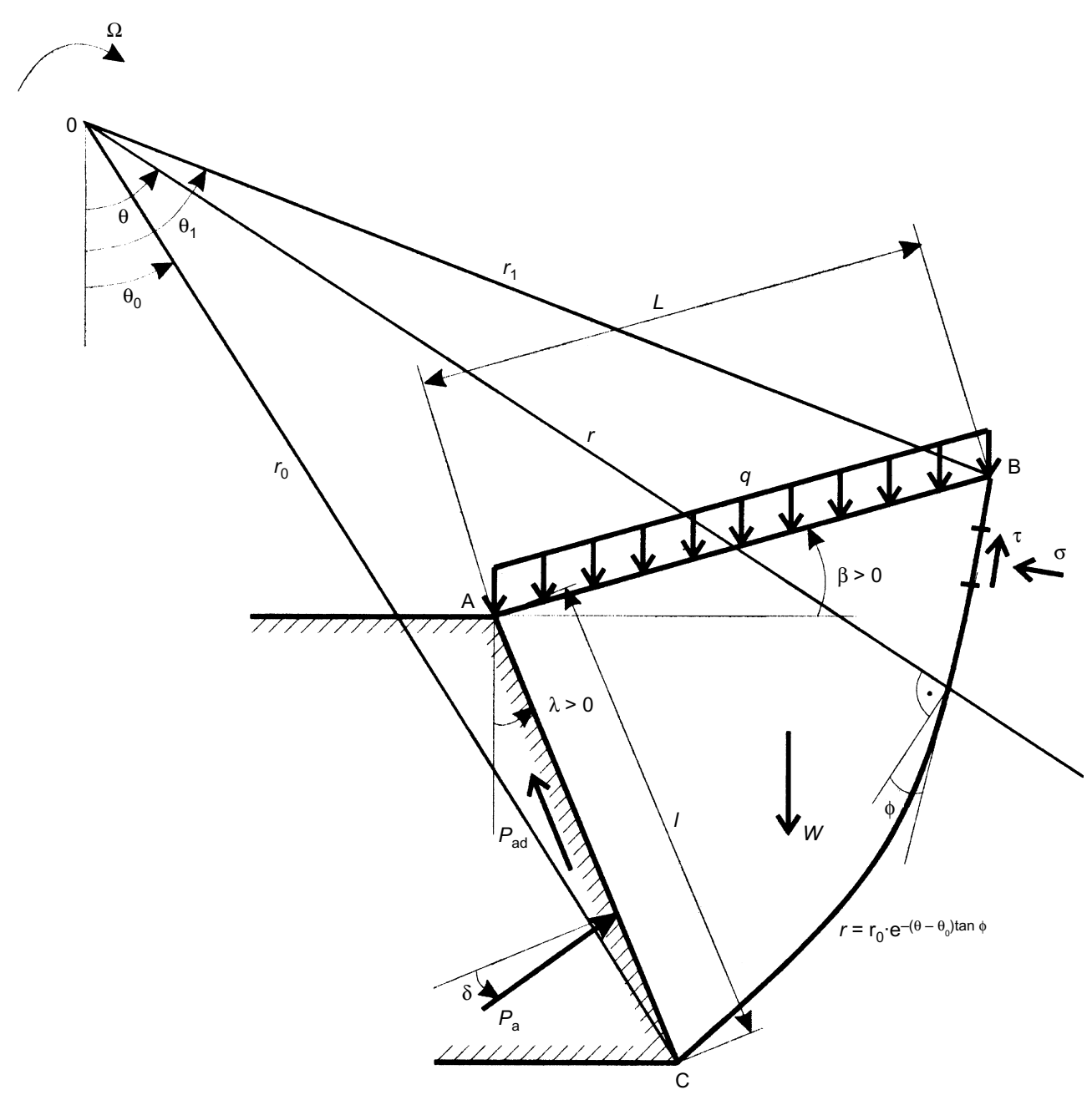

(a) 


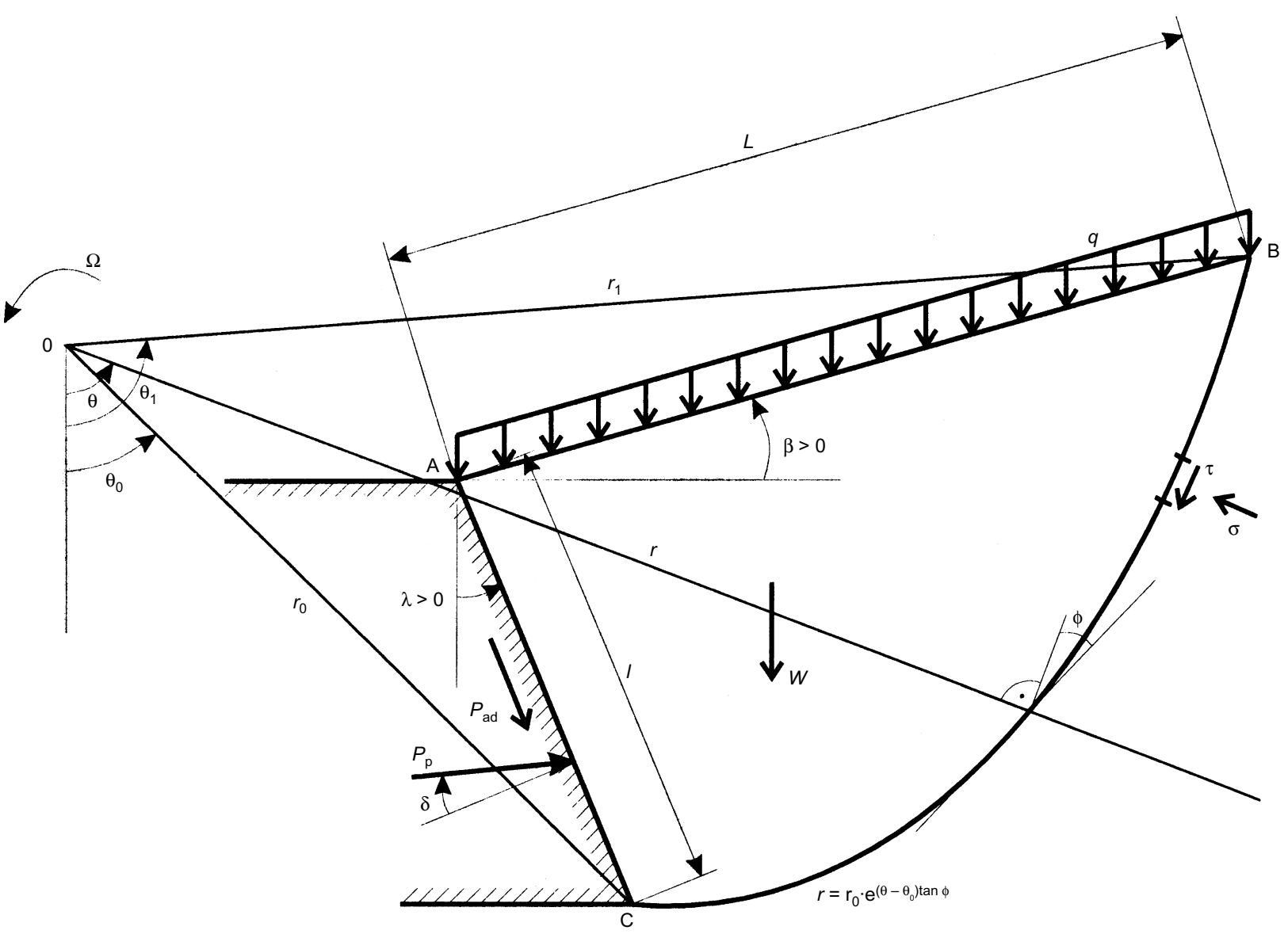

(b)

Fig. I. (continued)

region $\mathrm{ABC}$ is then found by simple algebraic summation, $\dot{W}_{\mathrm{OBC}}-\dot{W}_{\mathrm{OAB}}-\dot{W}_{\mathrm{OAC}}$. The steps of computation of the rate of work due to self-weight of the soil are essentially the same as those of an inclined slope considered by Chen. ${ }^{3}$ It is found that the rate of work due to the soil weight in the region $A B C$ is

$$
\dot{W}_{\text {soil }}=\gamma r_{0}^{3} \Omega\left(f_{1}-f_{2}-f_{3}\right)
$$

where $f_{1}, f_{2}$ and $f_{3}$ are non-dimensional functions, which are given in Appendix 1 .

\subsubsection{Rate of work of the active or passive force and the} adhesive force. The rate of work of the active or passive force $\left(P_{\mathrm{a}}\right.$ or $\left.P_{\mathrm{p}}\right)$ and the adhesive force, $P_{\mathrm{ad}}$, can be expressed as follows:

$$
\dot{W}_{\left(P_{\mathrm{a}} \text { or } P_{p}\right), P_{\mathrm{ad}}}=P_{\mathrm{a}, \mathrm{p}} r_{0} \Omega f_{4}+c r_{0}^{2} \Omega f_{5}
$$

where $f_{4}$ and $f_{5}$ are non-dimensional functions, which are given in Appendix 1. It should be mentioned that the active or passive force is assumed to act at the lower third of the wall length for the calculation of the coefficients $K_{\mathrm{a} \gamma}$ and $K_{\mathrm{p} \gamma}$. However, the computation of $K_{\mathrm{ac}}, K_{\mathrm{pc}}, K_{\mathrm{aq}}$ and $K_{\mathrm{pq}}$ is based on the assumption that the point of application of the active or passive force is applied at the middle of the wall length. These hypotheses are in conformity with the classical earth pressure distributions, and allow direct comparison with existing solutions.

2.1.3. Rate of work of the surcharge loading. The rate of work of the surcharge loading $q$ can be expressed as follows:

where $f_{6}$ is a non-dimensional function, which is given in Appendix 1.

The total rate of work of the external forces is the summation of these three contributions-that is, equations (1), (2) and (3):

$$
\sum[\dot{W}]_{\text {ext }}=\dot{W}_{\text {soil }}+\dot{W}_{\left(P_{\mathrm{a}} \text { or } P_{p}\right), P_{\text {ad }}}+\dot{W}_{q}
$$

\subsection{Rate of energy dissipation}

Since no general plastic deformation of the soil is permitted to occur, the energy is dissipated solely at the velocity discontinuity surface BC between the material at rest and the material in motion. The rate of energy dissipation per unit area of a velocity discontinuity can be expressed $\mathrm{as}^{3}$ 
where $V$ is the velocity that makes an angle $\phi$ with the velocity discontinuity. The total rate of energy dissipation along $\mathrm{BC}$ can be expressed as follows:

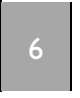

$$
\dot{D}_{B C}=c r_{0}^{2} \Omega f_{7}
$$

where $f_{7}$ is a non-dimensional function, which is given in Appendix 1.

\subsection{Energy balance equation}

By equating the total rate of work of external forces (equation (4)) to the total rate of energy dissipation (equation (6)), we have

$7 \gamma r_{0}^{3}\left(f_{1}-f_{2}-f_{3}\right)+P_{\mathrm{a}, \mathrm{p}} r_{0} f_{4}+c r_{0}^{2} f_{5}+q r_{0}^{2} f_{6}=c r_{0}^{2} f_{7}$

The energy balance equation of the rotational log-spiral mechanism (i.e. equation (7)) is identical to the moment equilibrium equation about the centre of the log-spiral. It should be emphasised that the log-spiral function has a particular property, that the resultant of the forces $(\sigma \cdot \mathrm{d} l)$ and $(\tan \phi \cdot \sigma \cdot \mathrm{d} l)$ passes through the pole of the spiral. Hence the moment equilibrium equation of the soil mass in motion about the centre of the log-spiral is independent of the normal stress distribution along the slip surface. Based on equation (7), the active and passive forces can be expressed respectively as follows:

$$
P_{a}=K_{\mathrm{a} \gamma} \frac{\gamma l^{2}}{2}+K_{\mathrm{aq}} q l-K_{\mathrm{ac}} c l
$$

$$
P_{p}=K_{\mathrm{p} \gamma} \frac{\gamma l^{2}}{2}+K_{\mathrm{pq}} q l+K_{\mathrm{pc}} c l
$$

where $K_{\mathrm{a} \gamma}, K_{\mathrm{p} \gamma}, K_{\mathrm{aq}}, K_{\mathrm{pq}}, K_{\mathrm{ac}}$ and $K_{\mathrm{pc}}$ are the earth pressure coefficients. The coefficients $K_{\gamma}, K_{\mathrm{q}}$ and $K_{\mathrm{c}}$ represent respectively the effect of soil weight, vertical surcharge loading and cohesion, and the subscripts a and p represent the active and passive cases respectively. These coefficients are given as follows, using the lower sign for the passive case:

$$
-K_{a \gamma}=K_{p \gamma}=\frac{2}{\left(\frac{l}{r_{0}}\right)^{2}} \cdot \frac{\left(f_{1}-f_{2}-f_{3}\right)}{f_{4}}
$$

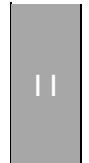

$$
-K_{a q}=K_{p q}=\frac{1}{\frac{l}{r_{0}}} \cdot \frac{f_{6}}{f_{4}}
$$

For a surcharge loading $q_{0}$ normal to the ground surface, the active and passive earth pressure coefficients, $K_{\mathrm{aq0}}$ and $K_{\mathrm{pq} 0}$, are given as follows:

$$
K_{\mathrm{aq} 0, \mathrm{pq} 0}= \pm \frac{1}{\frac{l}{r_{0}}} \cdot \frac{f_{8}}{f_{4}}
$$

where $f_{8}$ is a non-dimensional function, which is given in Appendix 1.

\section{NUMERICAL RESULTS}

The most critical earth pressure coefficients can be obtained by numerical maximisation of the coefficients $K_{\text {a } \gamma}, K_{\text {aq }}$ and $K_{\text {aq0 }}$ and minimisation of the coefficients $K_{\mathrm{ac}}, K_{\mathrm{p} \gamma}, K_{\mathrm{pq}}, K_{\mathrm{pq} 0}$ and $K_{\mathrm{pc}}$. These optimisations are made with regard to the parameters $\theta_{0}$ and $\theta_{1}$. The procedure can be performed using the optimisation tool available in most spreadsheet software packages. In this paper the Solver optimisation tool of Microsoft Excel has been used. Two computer programs have been developed using Visual Basic for Applications (VBA) to define the active and passive earth pressure coefficients as functions of the two angular parameters $\theta_{0}$ and $\theta_{1}$ defined in Fig. 1.

In the following sections, the passive and active earth pressure coefficients obtained from the present analysis are presented and compared with those given by other authors. Then a demonstration of the implementation of earth pressure coefficients as user-defined functions in Microsoft Excel Visual Basic is presented. An illustrative example shows the easy use of spreadsheets in optimisation problems. The paper ends with the presentation of two design tables giving some values of the active and passive earth pressure coefficients for practical use in geotechnical engineering.

\section{I. Passive earth pressure coefficients}

There are a great many solutions for the passive earth pressure problem in the literature based on

(a) the limit equilibrium method ${ }^{4-15}$

(b) the slip line method ${ }^{16-20}$

(c) limit analysis theory. ${ }^{2,21-28}$

The tendency today in practice is to use the values given by Kérisel and Absi. ${ }^{29}$

3.1.1. Comparison with Rankine solution. For the general case of an inclined wall and a sloping backfill $(\lambda / \phi \neq 0, \beta / \phi \neq 0)$, the Rankine passive earth pressure is inclined at an angle $\alpha$ with the normal to the wall irrespective of the angle of friction at the soil-wall interface, ${ }^{30}$ where

$$
\tan \alpha=\frac{\sin \left(\omega_{\beta}+\beta-2 \lambda\right) \sin \phi}{1+\sin \phi \cos \left(\omega_{\beta}+\beta-2 \lambda\right)}
$$




$$
\sin \omega_{\beta}=\frac{\sin \beta}{\sin \phi}
$$

The inclination of the slip surface with the horizontal direction is given as follows:$$
\xi=\frac{\omega_{\beta}+\beta}{2}+\frac{\pi}{4}-\frac{\phi}{2}
$$

and the coefficient $K_{\mathrm{p} \gamma}$ is given by

$$
17 \quad K_{\mathrm{p} \gamma}=\frac{\cos (\lambda-\beta) \sin \omega_{\beta}}{\cos \alpha \sin \left(\omega_{\beta}-\beta\right)}\left[1+\sin \phi \cos \left(\omega_{\beta}+\beta-2 \lambda\right)\right]
$$

In order to validate the results of the present analysis, one considers a soil-wall friction angle $\delta$ equal to the $\alpha$ value given by equation (14). The numerical solutions obtained by the computer program have shown that, in these cases, the present results are similar to the exact solutions given by Rankine (that is, equations (16) and (17)); the log-spiral slip surface degenerates to a planar surface with radii approaching infinity.

It should be emphasised that the results obtained from the computer program indicate that the coefficient $K_{\mathrm{pc}}$ is related to the coefficient $K_{\mathrm{pq} 0}$ by the following relationship (cf. Caquot's theorem of corresponding states ${ }^{31}$ ):

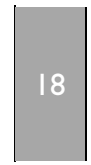

$$
K_{\mathrm{pc}}=\frac{K_{\mathrm{pq} 0}-\frac{1}{\cos \delta}}{\tan \phi}
$$

Also, it should be mentioned that the critical angular parameters $\theta_{0}$ and $\theta_{1}$ obtained from the minimisation of both $K_{\mathrm{pq} 0}$ and $K_{\mathrm{pc}}$ give exactly the same critical geometry.

\subsubsection{Comparison with Kérisel and Absi. Figures 2 and 3} show the comparison of the present solutions of $K_{\mathrm{p} \gamma}$ and $K_{\mathrm{pq}}$ with those of Kérisel and $\mathrm{Absi}^{29}$ for the case of a vertical wall and an inclined backfill, and for the case of an inclined wall and a horizontal backfill respectively, when $\phi=40^{\circ}$.

For the $K_{\mathrm{p} \gamma}$ coefficient, the present results are greater than those of Kérisel and Absi. However, the maximum difference does not exceed 13\%. For the $K_{\mathrm{pq}}$ coefficient, the present solutions continue to be greater than those of Kérisel and Absi; a maximum difference of $22 \%$ is obtained for the extreme case when $\phi=40^{\circ}, \delta / \phi=1, \beta / \phi=0$ and $\lambda=-30^{\circ}$.

To conclude, the present solutions of $K_{\mathrm{p} \gamma}$ and $K_{\mathrm{pq}}$ are greater than the ones given by Kérisel and Absi. However, for practical configurations $\left(\phi \leqslant 40^{\circ}, 1 / 3 \leqslant \delta / \phi \leqslant 2 / 3, \beta / \phi \leqslant 1 / 3\right.$ and $\lambda=0^{\circ}$ ), the maximum difference does not exceed $5 \%$ for $K_{\mathrm{p} \gamma}$ and $7 \%$ for $K_{\mathrm{pq}}$.

\subsubsection{Comparison with the existing upper-bound}

solutions. Rigorous upper-bound solutions of the passive earth
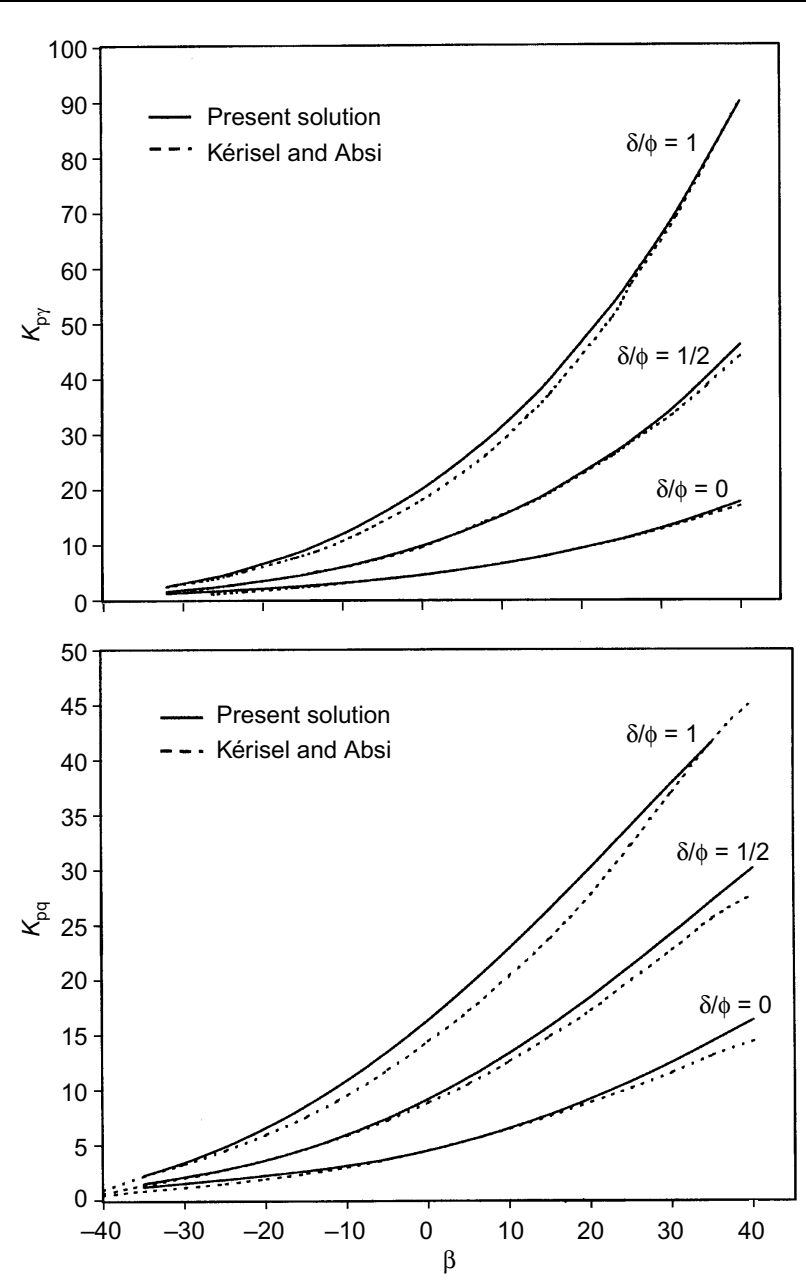

Fig. 2. Comparison of present $K_{p y}$ and $K_{p q}$ coefficients with those of Kérisel and $\mathrm{Absi}^{24}$ (for vertical wall and inclined backfill)

pressure problem are proposed in the literature by Chen and Rosenfarb ${ }^{23}$ and Soubra. ${ }^{27}$ Chen and Rosenfarb considered six translational failure mechanisms and showed that the logsandwich mechanism gives the least (that is, the best) upperbound solutions. Recently, Soubra ${ }^{27}$ considered a translational multiblock failure mechanism and improved significantly the existing upper-bound solutions given by the log-sandwich mechanism for the $K_{\mathrm{p} \gamma}$ coefficient, since he obtained smaller upper bounds. The improvement (that is, the reduction relative to Chen and Rosenfarb's upper-bound solution) attains $21 \%$ when $\phi=45^{\circ}, \delta / \phi=1, \beta / \phi=1$ and $\lambda=-15^{\circ}$.

The results of $K_{\mathrm{p} \gamma}$ and $K_{\mathrm{pq}}$ given by the present rotational failure mechanism and those given by Soubra ${ }^{27}$ using a translational failure mechanism are presented in Fig. 4 for the general case of an inclined wall and a sloping backfill when $\phi=45^{\circ}$ and $\delta / \phi=1$.

For the $K_{\mathrm{p} \gamma}$ coefficient, the present upper-bound solutions are smaller (that is, better) than those of Soubra. ${ }^{27}$ The improvement (that is, the reduction relative to Soubra's upperbound solution) is $27 \%$ when $\phi=45^{\circ}, \delta / \phi=1, \beta / \phi=1$ and $\lambda=-15^{\circ}$. For the $K_{\mathrm{pq}}$ coefficient, it should be mentioned that the values obtained by Soubra ${ }^{27}$ are identical to those given by Kérisel and $\mathrm{Absi}^{29}$ and correspond to the exact solutions for a 

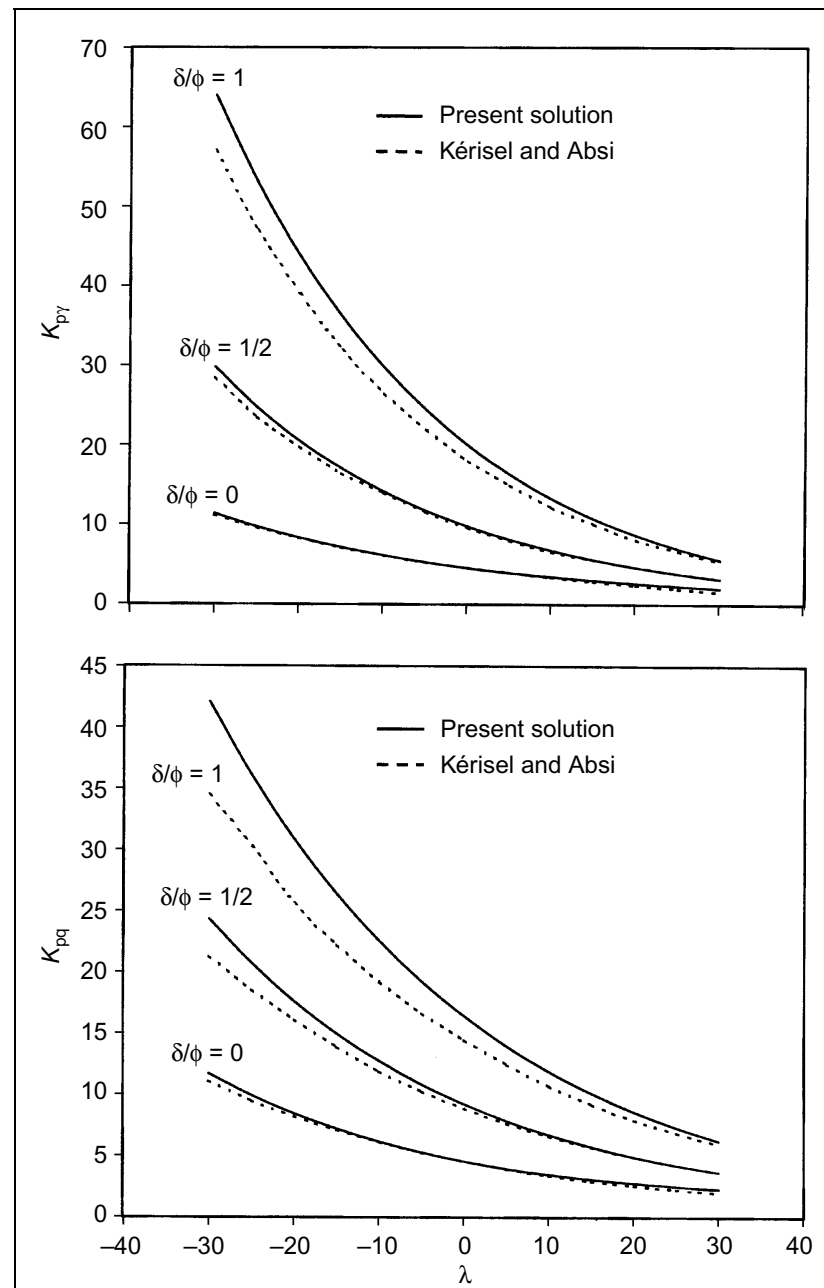

Fig. 3. Comparison of present $K_{\mathrm{p} \gamma}$ and $K_{\mathrm{pq}}$ coefficients with those of Kérisel and Absi ${ }^{29}$ (for inclined wall and horizontal backfill)

weightless soil. The present upper-bound solutions of the $K_{\mathrm{pq}}$ coefficient are greater than those of Soubra ${ }^{27}$ and thus overestimate the exact solutions. However, for practical configurations $\left(\phi \leqslant 40^{\circ}, 1 / 3 \leqslant \delta / \phi \leqslant 2 / 3, \beta / \phi \leqslant 1 / 3\right.$ and $\lambda=0^{\circ}$ ) the maximum difference does not exceed $7 \cdot 5 \%$.

\subsection{Active earth pressure coefficients}

As in the case of passive earth pressures, the numerical solutions obtained by the computer program have shown that the present model gives the exact solutions proposed by Rankine (when they exist). In these cases, the log-spiral slip surface degenerates to a planar surface with radii approaching infinity. Also, it should be mentioned that the following relationship between $K_{\text {ac }}$ and $K_{\text {aq0 }}$ is valid in the present analysis:

$$
K_{\mathrm{ac}}=\frac{\frac{1}{\cos \delta}-K_{\mathrm{aq} 0}}{\tan \phi}
$$

and that the calculation of $K_{\mathrm{aq} 0}$ and $K_{\mathrm{ac}}$ gives exactly the same critical geometry.

3.2.1. Comparison with Kérisel and Absi. Figures 5 and 6 show the comparison of the present solutions of $K_{\mathrm{a} \gamma}$ and $K_{\mathrm{aq}}$
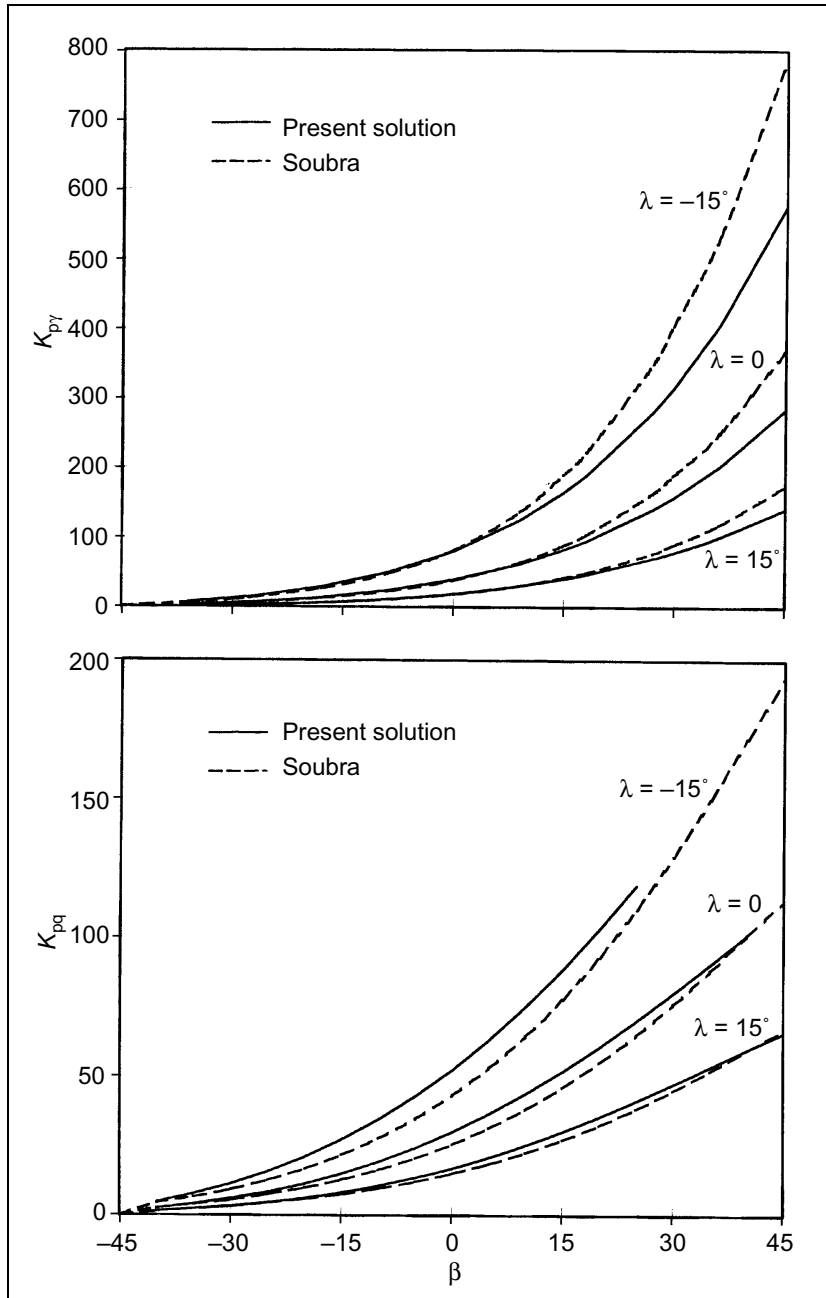

Fig. 4. Comparison of present $K_{\mathrm{p} y}$ and $K_{\mathrm{pq}}$ coefficients with those of Soubra

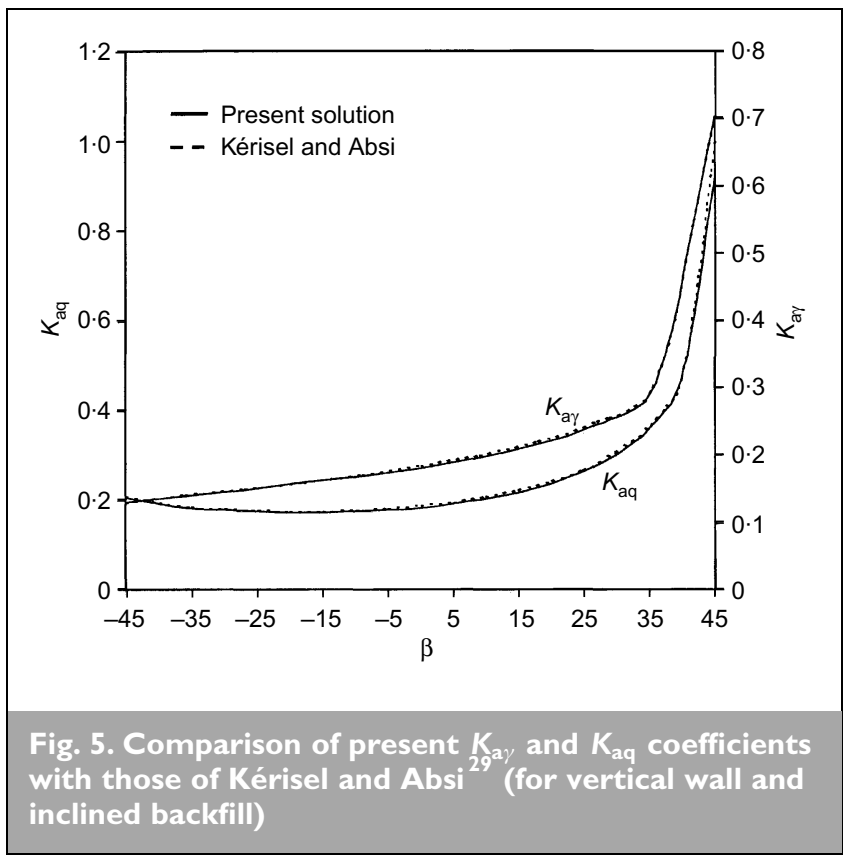

with those of Kérisel and $\mathrm{Absi}^{29}$ in the case of a vertical wall and an inclined backfill, and in the case of an inclined wall and a horizontal backfill respectively, when $\phi=45^{\circ}$ and $\delta / \phi=1$. 


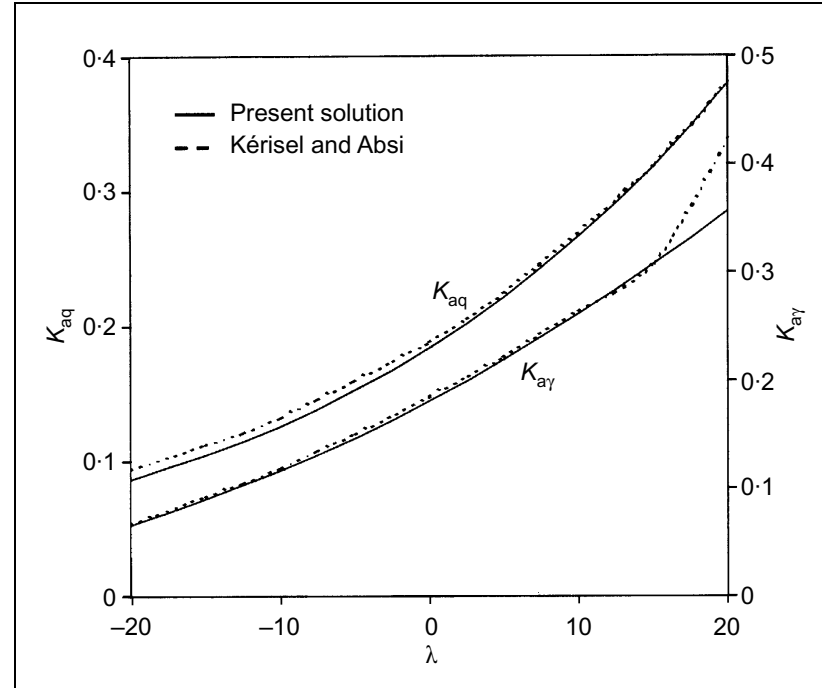

Fig. 6. Comparison of present $K_{\mathrm{ay}}$ and $K_{\mathrm{aq}}$ coefficients with those of Kérisel and $A \mathrm{Absi}^{29}$ (for inclined wall and horizontal backfill)

The present results are smaller than those of Kérisel and Absi. For the $K_{\mathrm{a} \gamma}$ coefficient, the maximum difference does not exceed $3 \%$ when $\lambda \leqslant 15^{\circ}$; however, for $\lambda=20^{\circ}$ a significant difference is observed. After careful examination of the values proposed by Kérisel and Absi for similar configurations (see for instance their values for $\delta / \phi=0.66$ or 0 ), it seems that their $K_{\mathrm{a} \gamma}$ value for $\phi=45^{\circ}, \delta / \phi=1, \beta=0^{\circ}$ and $\lambda=20^{\circ}$ is not correct. For the $K_{\text {aq }}$ coefficient the underestimation does not exceed $8 \%$.

The preceding comparisons allow one to conclude that, for practical configurations $\left(\phi \leqslant 40^{\circ}, \delta / \phi \leqslant 1, \beta / \phi \geqslant-1 / 3\right.$ and $\lambda=0^{\circ}$ ), there is good agreement with the currently used results of Kérisel and Absi for both $K_{\mathrm{a} \gamma}$ and $K_{\mathrm{aq}}$. The maximum difference does not exceed 3\%.
Module and, in the module sheet, typing 'Option explicit ..., etc. The functions are simple and self-explanatory.

(b) As shown in Fig. 7, cells C5, C6, C7 and C8 are input data that define the mechanical and geometrical parameters $\phi$, $\delta, \lambda$ and $\beta$. Cells $\mathrm{C} 12$ and $\mathrm{C} 13$ contain values of angular parameters of the log-spiral slip surface $\theta_{0}$ and $\theta_{1}$. Finally, cell C19 contains the formula to compute the passive earth pressure coefficient $K_{\mathrm{p} \gamma}$. Arbitrary values were initially entered in cells C12 and C13 for $\theta_{0}$ and $\theta_{1}$, say 0.5 for $\theta_{0}$ and 1.5 for $\theta_{1}$.

(c) Invoke the Solver tool by clicking Tools/Solver. Fig. 8 shows the Solver dialog box. To calculate the $K_{\mathrm{p} \gamma}$ coefficient, set the $\mathrm{C} 19$ cell 'equal to' minimum, 'by changing' cells $\mathrm{C} 12$ and $\mathrm{C} 13$, namely $\theta_{0}$ and $\theta_{1}$, 'subject to' the constraints that $\mathrm{C} 13 \geqslant \mathrm{C} 12+0.0001\left(\theta_{1}>\theta_{0}\right)$, $\mathrm{C} 12 \leqslant 3 \cdot 14\left(\theta_{0} \leqslant \pi\right), \mathrm{C} 13 \leqslant 3 \cdot 14\left(\theta_{1} \leqslant \pi\right)$, $\mathrm{C} 13 \geqslant 0\left(\theta_{1} \geqslant 0\right)$ and $\mathrm{C} 19 \geqslant 0\left(K_{\mathrm{p} \gamma} \geqslant 0\right)$.

If Solver reports a converged solution, one should accept the solution and re-invoke Solver, until it reports it has 'found a solution'. It should be mentioned that the initial values of $\theta_{0}$ and $\theta_{1}$ may influence the ability of the Solver to find a solution. This need for judicious choice of starting values of $\theta_{0}$ and $\theta_{1}$ is not a major inconvenience because different starting values can be tried with ease using the proposed spreadsheet approach. The appealing feature of the spreadsheet approach is that once the spreadsheet is set up as shown in Fig. 7, running other problems with different geometry and soil properties merely requires changing the input data (that is, $\phi, \delta, \beta$ and $\lambda$ ).

\section{I. Illustrative example}

Consider the following characteristics: $\phi=40^{\circ}, \delta / \phi=2 / 3$, $\beta / \phi=0$ and $\lambda=0^{\circ}$. Initial values of $\theta_{0}$ and $\theta_{1}$ are arbitrarily chosen, say 0.5 for $\theta_{0}$ and 1.5 for $\theta_{1}$. Fig. 7 shows the critical coefficient $K_{\mathrm{p} \gamma}=12.59$ and the corresponding critical slip surface.

\section{IMPLEMENTATION OF USER-DEFINED FUNCTIONS IN VISUAL \\ BASIC FOR \\ APPLICATIONS, AND THE USE OF SOLVER}

To implement the functions defining the passive earth pressure coefficients and to run the Solver optimisation tool of Microsoft Excel, one has to follow the following steps (for the active case, use the appropriate equations given in Appendix 1):

(a) Create the user-defined functions shown in Appendix 2. This is done in Microsoft Excel 97 by first clicking Tools/ Macro/Visual Basic Editor and then clicking Insert/

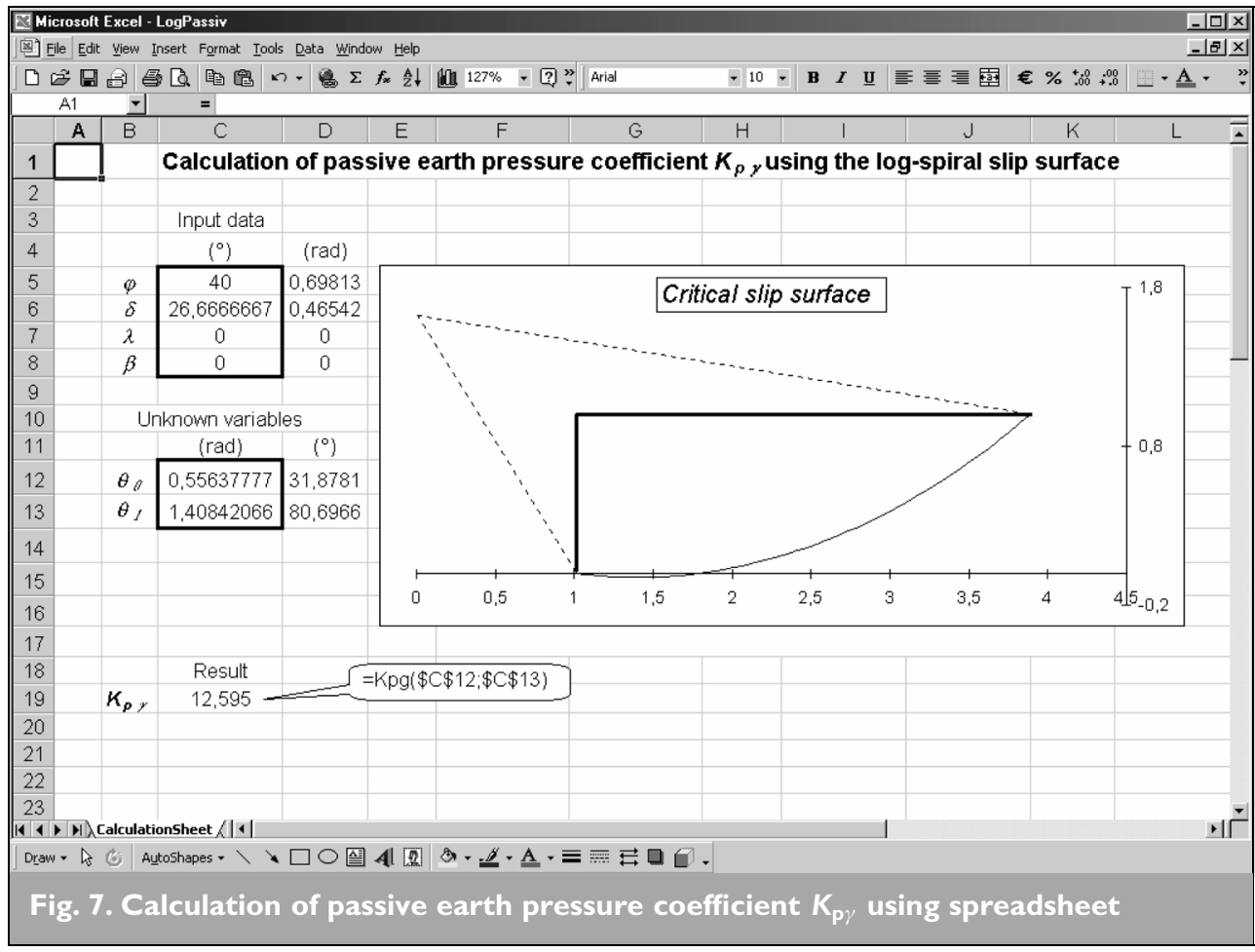




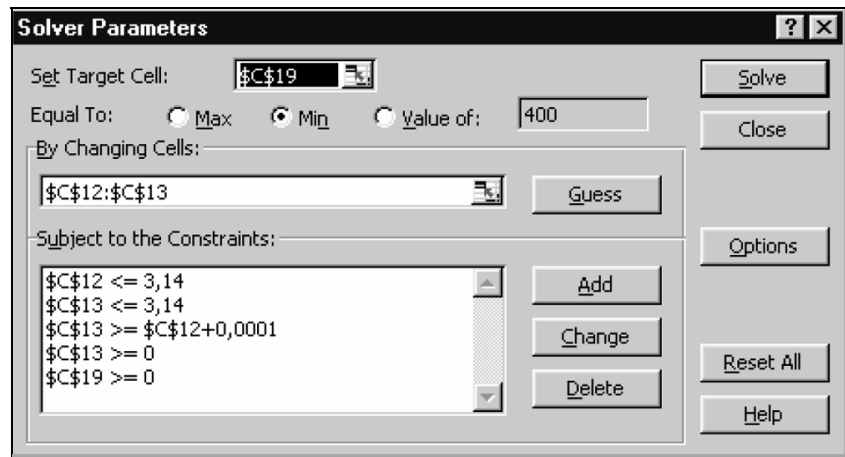

Fig. 8. Solver dialog box

\section{DESIGN TABLES}

Tables 1 and 2 present the coefficients $K_{\mathrm{p} \gamma}, K_{\mathrm{pq}}, K_{\mathrm{pc}}, K_{\mathrm{a} \gamma}, K_{\mathrm{aq}}$ and $K_{\mathrm{ac}}$ obtained from the computer programs for practical use in geotechnical engineering. These values are given for $\phi$ ranging from $20^{\circ}$ to $40^{\circ}$, for five values of $\delta / \phi$, for $\lambda=0^{\circ}$ and for four values of $\beta / \phi$. For practical configurations, the passive (or active) earth pressure coefficients are given for negative (or positive) $\beta$ values.

\section{CONCLUSIONS}

A simple method using spreadsheet software has been proposed for computing the active and passive earth pressure coefficients. The method is based on the upper-bound theorem of limit analysis. The failure mechanism is of the rotational type. It is bounded by a log-spiral slip surface. The energy balance equation is shown to be equivalent to the moment equilibrium equation about the centre of the log-spiral. The present approach gives rigorous solutions for the active and passive earth pressures in the framework of the kinematical approach of limit analysis.

Numerical optimisation is performed automatically by a spreadsheet optimisation tool. The implementation of the proposed method has been illustrated using an example. Once the spreadsheet has been set up, the same template can be used for analysing other problems merely by changing the input data. The advantage of this method is its simplicity in use.

Comparison with the currently used solutions of Kérisel and $\mathrm{Absi}^{29}$ leads to the following conclusions:

(a) For the passive case, the present solutions of $K_{\mathrm{p} \gamma}$ and $K_{\mathrm{pq}}$ are greater than those given by Kérisel and Absi. ${ }^{29}$

However, for practical configurations $\left(\phi \leqslant 40^{\circ}, 1 / 3 \leqslant \delta / \phi\right.$ $\leqslant 2 / 3, \beta / \phi \leqslant 1 / 3$ and $\lambda=0^{\circ}$ ), the maximum difference does not exceed 5\% for $K_{\mathrm{p} \gamma}$ and $7 \%$ for $K_{\mathrm{pq}}$.

(b) For the active case, the present solutions of $K_{\mathrm{a} \gamma}$ and $K_{\mathrm{aq}}$ allow one to conclude that for practical configurations $\left(\phi \leqslant 40^{\circ}, \delta / \phi \leqslant 1, \beta / \phi \geqslant-1 / 3\right.$ and $\left.\lambda=0^{\circ}\right)$, there is good agreement with the currently used results of Kérisel and Absi. The maximum difference does not exceed 3\%.

On the other hand, the present analysis improves the best upper-bound solutions given in the literature by Soubra ${ }^{27}$ for the $K_{\mathrm{p} \gamma}$ coefficient. The improvement (that is, the reduction relative to Soubra's upper-bound solution) is $27 \%$ when $\phi=45^{\circ}, \delta / \phi=1, \beta / \phi=1$ and $\lambda=-15^{\circ}$. For the $K_{\mathrm{pq}}$ coefficient, the present analysis overestimates the upper-bound solutions given by Soubra. However, for practical configurations $\left(\phi \leqslant 40^{\circ}, 1 / 3 \leqslant \delta / \phi \leqslant 2 / 3, \beta / \phi \leqslant 1 / 3\right.$ and $\lambda=0^{\circ}$ ) the maximum difference does not exceed $7 \cdot 5 \%$.

Numerical results of the active and passive earth pressure coefficients are given in a tabular form for practical use. The proposed method, being simple and rigorous, may be an attractive alternative to other existing solutions, and can be easily extended to other stability problems in geotechnical engineering.

\section{APPENDIX I}

The non-dimensional functions $f_{1}, f_{2}, \ldots, f_{8}$ are given as follows, using the lower sign for the passive case:

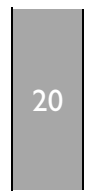
$f_{1}= \pm\left[\begin{array}{c}\mu e^{\mu 3\left(\theta_{1}-\theta_{0}\right) \tan \phi}\left(3 \tan \phi \cdot \sin \theta_{1} \pm \cos \theta_{1}\right) \\ \pm 3 \tan \phi \cdot \sin \theta_{0}+\cos \theta_{0}\end{array}\right]$

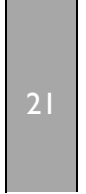

$$
\begin{aligned}
f_{2}= & \pm \frac{1}{6} \frac{L}{r_{0}}\left(2 \sin \theta_{0}-2 \frac{l}{r_{0}} \sin \lambda+\frac{L}{r_{0}} \cos \beta\right) \\
& \cdot \cos \left(\theta_{1}-\beta\right) \cdot e^{\mp\left(\theta_{1}-\theta_{0}\right) \tan \phi}
\end{aligned}
$$

$$
f_{3}= \pm \frac{1}{6} \frac{l}{r_{0}} \sin \left(\theta_{0}-\lambda\right) \cdot\left(2 \sin \theta_{0}-\frac{l}{r_{0}} \sin \lambda\right)
$$

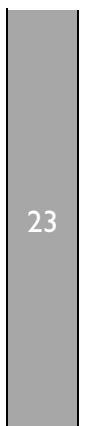

$$
f_{4}=\left\{\begin{array}{l}
\cos (\delta \pm \lambda)\left(\cos \theta_{0}-\frac{1}{3} \frac{l}{r_{0}} \cos \lambda\right) \\
\pm \sin (\delta \pm \lambda)\left(\sin \theta_{0}-\frac{1}{3} \frac{l}{r_{0}} \sin \lambda\right) \\
\quad \text { for } K_{\lambda} \\
\cos (\delta \pm \lambda)\left(\cos \theta_{0}-\frac{1}{2} \frac{l}{r_{0}} \cos \lambda\right) \\
\pm \sin (\delta \pm \lambda)\left(\sin \theta_{0}-\frac{1}{2} \frac{l}{r_{0}} \sin \lambda\right) \\
\text { for } K_{\mathrm{q}}, K_{\mathrm{q} 0} \text { and } K_{\mathrm{c}}
\end{array}\right.
$$

$$
f_{5}=\frac{l}{r_{0}} \frac{\tan \delta}{\tan \phi} \cdot \sin \left(\lambda-\theta_{0}\right)
$$

$$
f_{6}=\mp \frac{L}{r_{0}}\left(-\sin \theta_{0}+\frac{l}{r_{0}} \sin \lambda-\frac{1}{2} \frac{L}{r_{0}} \cos \beta\right)
$$




\begin{tabular}{|c|c|c|}
\hline & - & 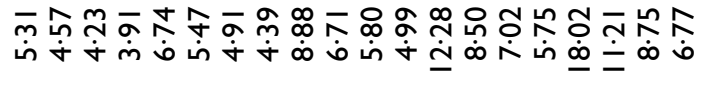 \\
\hline & $\stackrel{m}{\sim}$ & 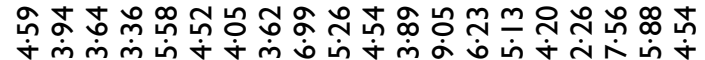 \\
\hline$\check{\Sigma}^{u}$ & $\frac{0}{2} \stackrel{n}{=}$ & 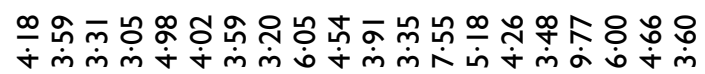 \\
\hline & $\stackrel{m}{-}$ & 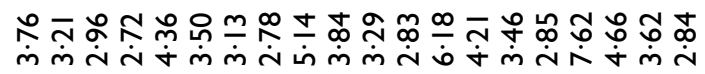 \\
\hline & 0 & 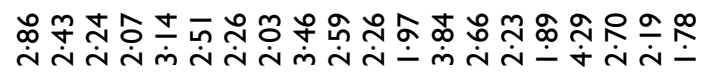 \\
\hline & - & 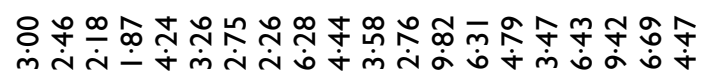 \\
\hline & $\stackrel{m}{\sim}$ & 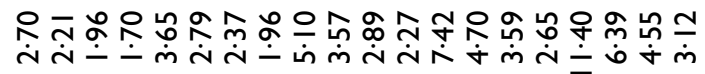 \\
\hline$\Sigma^{\sigma}$ & $\frac{0}{2} \stackrel{1}{=}$ & 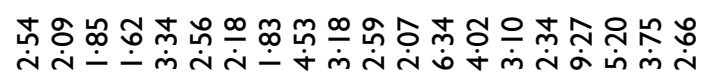 \\
\hline & $\stackrel{m}{-}$ & 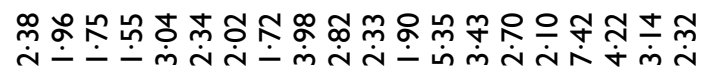 \\
\hline & 0 & 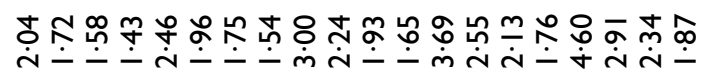 \\
\hline & - & 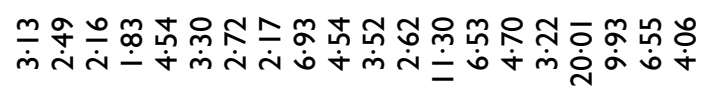 \\
\hline & $\stackrel{m}{\sim}$ & 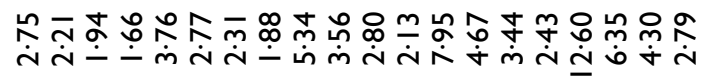 \\
\hline$\stackrel{\grave{z}}{2}$ & $\frac{0}{a}=$ & 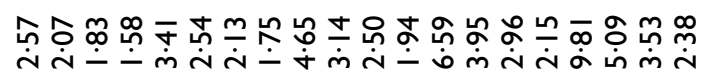 \\
\hline & $\stackrel{m}{-}$ & 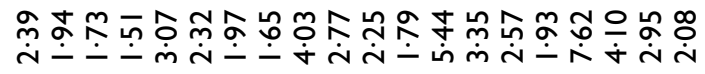 \\
\hline & $\circ$ & 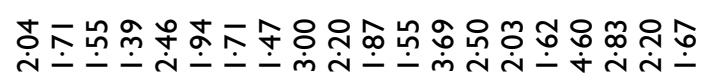 \\
\hline & $\frac{2}{a}$ & 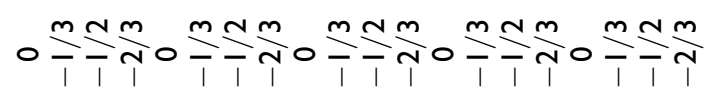 \\
\hline$\theta$ & & $\stackrel{\sim}{\sim}$ \\
\hline
\end{tabular}




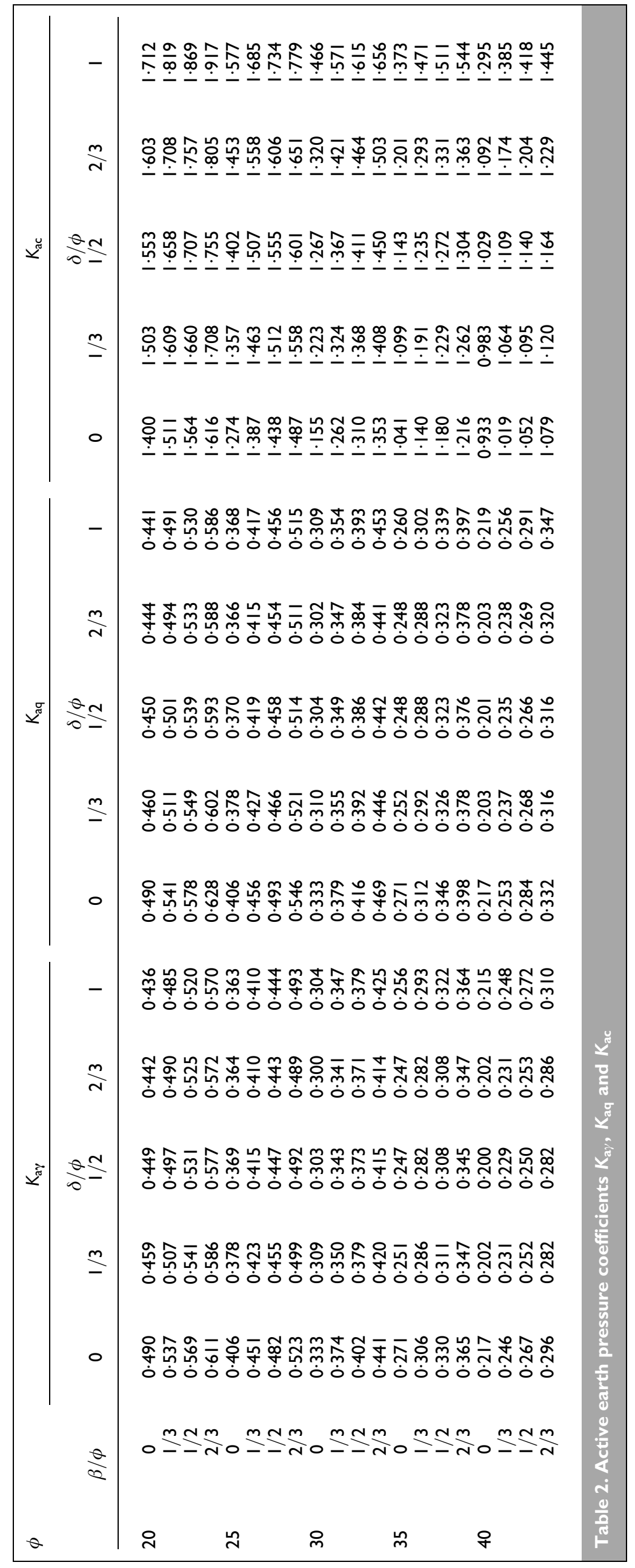


where

\section{APPENDIX 2}

The user-defined functions for passive earth pressure coefficients coded in Microsoft Excel Visual Basic are as follows:

' Program for evaluation of Kpgama, Kpc and $\mathrm{Kpq}$ for rotational

' mechanism using log-spiral slip surface

Option Explicit ' All variables must be declared

' Definition of the global constants

Public Const $\mathrm{Pi}=3.141592654$

- Variables

Public Phi As Double ' internal friction angle of the soil

Public Delta As Double ' angle of friction between soil and wall

Public Lambda As Double ' inclination of the wall

Public Beta As Double ' inclination of the backfill

Public Sl_r0 As Double' $1 / r 0$

Public CL_ro As Double' L/r0

' Unknown variables

Public Theta0 As Double ' first unknown angle (in radians)

Public Thetal As Double' second unknown angle (in radians)

' Defining the initial values

Sub Define()

Phi $=$ Cells $(5,3)$.Value * Pi / 180\# ' Values from the cells

Delta $=\operatorname{Cells}(6,3) \cdot$ Value * $\mathrm{Pi} / 180 \#$

Lambda $=\operatorname{Cells}(7,3)$.Value $* \mathrm{Pi} / 180 \#$

Beta $=$ Cells $(8,3)$. Value * Pi / 180\#

Theta $0=\operatorname{Cells}(12,3) \cdot$ Value

Theta1 $=\operatorname{Cells}(13,3) \cdot$ Value

S1_r0 $=(-\operatorname{Exp}(($ Theta1 - Theta $) * \operatorname{Tan}($ Phi $)) * \operatorname{Cos}($ Theta1 - Beta $)$ -

+ Cos (Theta0 - Beta)) / Cos (Beta - Lambda)

CL_r0 $=(\operatorname{Exp}(($ Thetal - Theta0 $) * \operatorname{Tan}($ Phi $))$

* $(\operatorname{Sin}(\text { Theta } 1)-\operatorname{Cos}(\text { Theta }) * \operatorname{Tan}(\text { Lambda }))^{-}-$

$\operatorname{Sin}($ Theta0) + Cos (Theta0) * Tan (Lambda)) / _

$(\operatorname{Sin}($ Beta $) * \operatorname{Tan}($ Lambda $)+\operatorname{Cos}($ Beta $))$

End Sub

Function f_1() As Double

Dim C1\#, C2 \#

$\mathrm{C} 1=\operatorname{Exp}(3 \# *($ Theta1 - Theta $) * \operatorname{Tan}(\mathrm{Ph} i))$

$\mathrm{C} 2=3 \# *(9 \# *(\operatorname{Tan}(\mathrm{Ph} i)) \wedge 2+1)$

$f_{-1}=-(\mathrm{C} 1 *(3 \# * \operatorname{Tan}(\mathrm{Phi}) * \operatorname{Sin}($ Theta 1$)-\operatorname{Cos}($ Theta 1$))-$

$3 \# * \operatorname{Tan}(\mathrm{Phi}) * \operatorname{Sin}($ Theta 0$)+\operatorname{Cos}($ Theta 0$))$ / C2

End Function

$1 * * * * * * * * * * * * * * * * * * * * * * * * * * * * * * * * * * * * * * * * * * * * * * *$

Function f_2() As Double

Dim $\mathrm{C} 1 \#, \mathrm{C} 2 \#$

$\mathrm{C} 1=2 \# * \operatorname{Sin}($ Theta 0$)-2 \# * \mathrm{~S} I_{-}$r0 0 Sin (Lambda) + CL_r0 * Cos (Beta)

$\mathrm{C} 2=\mathrm{CL} \_r 0 * \operatorname{Cos}($ Theta1 - Beta $) * \operatorname{Exp}(($ Theta1 - Theta 0$) *$ Tan $($ Phi $))$

$\mathrm{f} \_2=-(1 \# / 6 \#) * \mathrm{C} 1 * \mathrm{C} 2$

End Function

Function f_3() As Double

f_3 $=-(1 \# / 6 \#) * S 1 \_r 0 * \sin (T h e t a 0-$ Lambda $) *-$

$(2 \#$ * Sin (Theta0) - SI_r0 * Sin (Lambda))

End Function

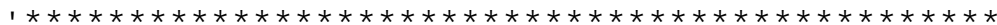

Function f_4_Kpg ( ) As Double

Dim C1\#, C2 $\#$

$\mathrm{C} 1=\operatorname{Cos}($ Delta - Lambda $) *\left(\operatorname{Cos}(\right.$ Theta 0$)-\mathrm{S} 1 \_r 0 / 3 \#$ * Cos (Lambda) $)$

$\mathrm{C} 2=\operatorname{Sin}($ Delta - Lambda $) *(\operatorname{Sin}($ Theta0) $-\operatorname{SI} r 0 / 3 \#$ * Sin (Lambda))

$\mathrm{f} \_4$ _Kpg $=\mathrm{C} 1-\mathrm{C} 2$

End Function 


\begin{tabular}{|c|}
\hline 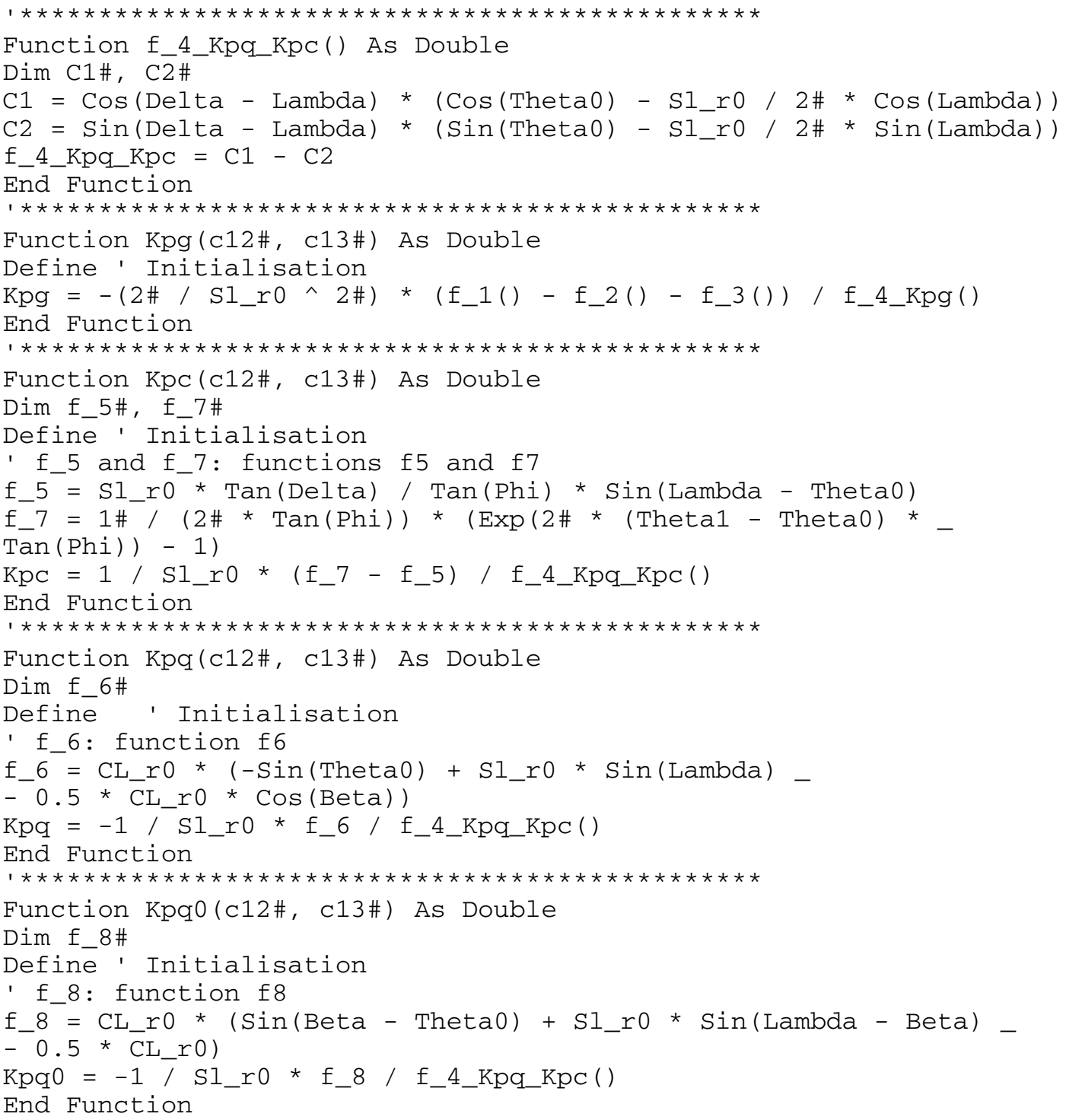 \\
\hline
\end{tabular}

\section{REFERENCES}

1. Coulomb C. A. Sur une application des règles de maximis et minimis à quelques problèmes de statique relatifs à l'architecture. Acad. R. Sci. Mém. Math. Phys., 1773, 7, 343-382.

2. SOUBRA A.-H., KASTNER R. and BenMansour A. Passive earth pressures in the presence of hydraulic gradients. Géotechnique, 1999, 49, No. 3, 319-330.

3. CHEN W. F. Limit Analysis and Soil Plasticity. Elsevier, Amsterdam, 1975.

4. TerZAghi K. Theoretical Soil Mechanics. Wiley, New York, 1943.

5. JANBU N. Earth pressure and bearing capacity calculations by generalised procedure of slices. Proceedings of the Fourth International Conference, International Society of Soil Mechanics and Foundation Engineering, 1957, 2, 207-213.

6. RowE P. W. Stress-dilatancy, earth pressures, and slopes. Journal of the Soil Mechanics and Foundation Division, ASCE, 1963, 89, No. SM3, 37-61.

7. LEE J. K. and MOORE P. J. Stability Analysis: Application to Slopes, Rigid and Flexible Retaining Structures. Selected Topics in Soil Mechanics. Butterworth, London, 1968.

8. PACKSHAW S. Earth Pressure and Earth Resistance: A
Century of Soil Mechanics. Institution of Civil Engineers, London, 1969.

9. SHIELDS D. H. and TOLUNAY A. Z. Passive pressure coefficients for sand by the Terzaghi and Peck method. Canadian Geotechnical Journal, 1972, 9, No. 4, 501-503.

10. SHIELDS D. H. and TolunaY A. Z. Passive pressure coefficients by method of slices. Journal of the Geotechnical Engineering Division, Proceedings of the ASCE, 1973, 99, No. SM12, 1043-1053.

11. SPENCER E. Forces on retaining walls using the method of slices. Civil Engineering, 1975, 18-23.

12. RAHARDJO H. and FredLUND D. G. General limit equilibrium method for lateral earth forces. Canadian Geotechnical Journal, 1984, 21, No. 1, 166-175.

13. Bilz P., FranKe D. and PietSCH C. Earth pressure of soils with friction and cohesion. Proceedings of the Eleventh International Conference on Soil Mechanics and Foundation Engineering, San Francisco, 1985, 2, 401-405.

14. Kumar, J. and SubBa RA0, K. S. Passive pressure coefficients, critical failure surface and its kinematic admissibility. Géotechnique, 1997, 47, 185-192.

15. DunCAN J. M. and MoKWA R. Passive earth pressures: theories and tests. Journal of Geotechnical and Geoenvironmental Engineering, 2001, 127, No. 3, 248-257. 
16. Caquot A. and KéRISEl J. Tables de poussée et de butée. Gauthier-Villars, Paris, 1948.

17. SoKolovski V. V. Statics of Soil Media. Butterworth, London, 1960.

18. Sokolovski V. V. Statics of Granular Media. Pergamon, New York, 1965.

19. GRAHAM J. Calculation of passive pressure in sand. Canadian Geotechnical Journal, 1971, 8, No. 4, 566-579.

20. Hettiaratchi R. P. and Reece A. R. Boundary wedges in two-dimensional passive soil failure. Géotechnique, 1975, 25, No. 2, 197-220.

21. LYSMER J. Limit analysis of plane problems in soil mechanics. Journal of Soil Mechanics and Foundation Division, ASCE, 1970, 96, No. SM4, 1311-1334.

22. LEE I. K. and HERINGTON J. R. A theoretical study of the pressures acting on a rigid wall by a sloping earth on rockfill. Géotechnique, 1972, 22, No. 1, 1-26.

23. CHEN W. F. and RoSEnFARB J. L. Limit analysis solutions of earth pressure problems. Soils and Foundations, 1973, 13, No. 4, 45-60.

24. BASUDHAR P. K., VAlSANGKAR A. J. and MAdHAV M. R. Optimal lower bound of passive earth pressure using finite elements and non-linear programming. International
Journal for Numerical and Analytical Methods in Geomechanics, 1979, 3, No. 4, 367-379.

25. CHEN W. F. and LIU X. L. Limit Analysis in Soil Mechanics. Elsevier, Amsterdam, 1990.

26. Soubra A.-H., KAStner R. and Benmansour A. Etude de la butée des terres en présence d'écoulement. Revue Française de Génie Civil, 1998, 2, No. 6, 691-707 (in French).

27. SOUBRA A.-H. Static and seismic passive earth pressure coefficients on rigid retaining structures. Canadian Geotechnical Journal, 2000, 37, No. 2, 463-478.

28. Soubra A.-H. and Regenass P. Three-dimensional passive earth pressures by kinematical approach. Journal of Geotechnical and Geoenvironmental Engineering, ASCE, 2000, 126, No. 11, 969-978.

29. KÉRISEL J. and ABSI E. Tables de poussée et de butée des terres, 3rd edn. Presses de l'Ecole Nationale des Ponts et Chaussées, 1990 (in French).

30. Costet J. and SAnglerat G. Cours pratique de mécanique des sols. Plasticité et calcul des tassements, 2nd edn. Dunod Technique Press, 1975 (in French).

31. CAQUOT A. Equilibre des massifs à frottement interne. Stabilité des terres pulvérulents et cohérents. GauthierVillars, Paris, 1934. 